\title{
Promoting experiential learning through the use of high-fidelity human patient simulators in midwifery: A qualitative study
}

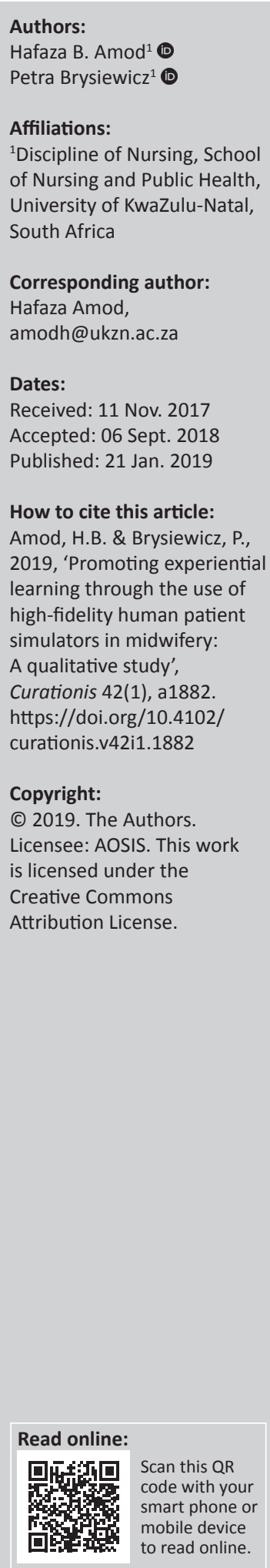

Background: The need to use innovative teaching and learning strategies in the nursing pedagogy is important in the 21st century. The challenges of clinical sites and opportunities for nursing students to gain clinical experience are a growing concern for many nurse educators. High-fidelity human patient simulators (HFHPS) are computerised mannequins that replicate a real-life patient, and when integrated into classroom teaching they allow students to become fully immersed into an almost real-life scenario.

Objectives: The aim of this study was to describe how HFHPS can promote experiential learning following the management of postpartum haemorrhage as a midwifery clinical emergency.

Method: A descriptive qualitative research approach was carried out in this study. The research setting was a local university in KwaZulu-Natal. The total population included all $(N=43)$ fourth-year baccalaureate of nursing undergraduate student midwives who participated as observers and/or role-players of a scenario role-play. An all-inclusive sampling was performed. There were 43 student midwives involved in the simulation teaching session with 6 of these students actively participating in each role-play at a time, while the remaining 37 observed. This occurred in two separate sessions and all the student midwives were involved in a debriefing session. These student midwives were then followed up and asked to participate in a focus group. The data in this article came from two separate focus groups which comprised 20 student midwives in total. Data were analysed using content analysis.

Results: Four categories emerged from the data, namely HFHPS offers a unique opportunity for student midwives to manage complex real-life emergencies; promotes reflection by allowing student midwives to reflect or review their roles, decisions and skills; allows student midwives to learn from their own experiences and encourages student midwives to try out what they learnt in a real-life situation.

Conclusion: High-fidelity human patient simulators can be used in a complex case scenario to promote experiential learning of a clinical emergency.

\section{Introduction}

The development of fundamental clinical skills is an important component in preparing students to meet the responsibilities of a midwife. Findings from studies conducted by Linder and Pulsipher (2008) and Sundler, Petterson and Berglund (2015) revealed that simulation has become an established pedagogy for teaching clinical skills, thus providing students the opportunity to gain essential skills in a 'real-life'-like environment. The need to use innovative teaching and learning strategies in the nursing pedagogy is important in the 21st century. The challenges of clinical sites and opportunities for nursing students to gain clinical experience are a growing concern for many nurse educators. Simulation experiences using high-fidelity human patient simulators (HFHPS) provide an effective teaching and learning approach as they allow students to become active and fully participative learners (Jeffries \& Jeffries 2012; Powell-Laney, Keen \& Hall 2012). High-fidelity human patient simulators are computerised mannequins that imitate real-life signs and symptoms such as breathing, pulse, blood pressure, moaning and blinking to enhance realism (Flood et al. 2011; Jeffries \& Jeffries 2012). This type of technology allows nurse educators an opportunity to design various case scenarios using advanced equipment and without fear of compromising patient safety. Through active learning or engagement, students are offered an opportunity to practise rare and/or complex emergencies in a safe and controlled environment (Boet et al. 2014; Lewis, Strachan \& Smith 2012). 
Jeffries and Jeffries (2012) state that ensuring active engagement in the learning process is important when designing and using simulation. Students can practise various procedural tasks and complex cognitive skills in a simulated setting and these skills can transfer to the workplace, thus enhancing patient care (Bruppacher et al. 2010; Phipps et al. 2012; Riley et al. 2011).

Getting students to 'learn by doing' offers students the opportunity to understand easy and complex skills through active participation (Farooq 2013). Kolb (2014) viewed learning as a continuous process of knowledge creation through the transformation of experience. Kolb's experiential learning theory (2014) addresses the provision of learning experience to meet the needs of all types of learners. He describes how information processing and learning occurs in cycles, and this process starts with concrete experiences in which students immerse themselves fully into a new experience that they consider to be stimulating or challenging. The second phase of reflective observation occurs when students observe and reflect on their concrete experience. This follows with the creation of logical theories through the integration of observation, which is termed as an abstract conceptualisation. The last phase, which is active experimentation, is when students apply these new theories during decision-making and problem-solving activities. When learners are able to execute all four stages of the cycle, effective learning takes place (Chan 2012; Stocker, Burmester \& Allen 2014; Wolfgram \& Quinn 2013). According to Zigmont, Kappus and Sudikoff (2011), the experiential learning process involves participation and analysis of key experiences. Yardley, Teunissen and Dornan (2012) define experiential learning as the construction of knowledge and meaning from real-life experiences. Hence, experiential learning is situated in a context that is relevant to the learners' own future careers.

In this study, the researcher used real-life people to play the roles of various healthcare team members as practised in a real-life emergency. Student midwives played the role of a registered midwife, enrolled nurse, student midwife, a medical doctor and a birth companion (Table 1). The scenario offered student midwives an opportunity to understand

TABLE 1: Gender demographics of participants.

\begin{tabular}{lll}
\hline Variables & Scenario 1 & Scenario 2 \\
\hline Role-players & & \\
Team leader (registered midwife) & Female & Female \\
Assistant 1 (student midwife) & Male & Female \\
Assistant 2 (student midwife) & Male & Female \\
Enrolled nurse & Female & Female \\
Husband (birth companion) & Male & Male \\
Doctor & Male & Male \\
Observers & & \\
37 students & 3 Male & 5 Male \\
& 34 Female & 32 Female \\
Debriefing & & \\
All participants $(N=43)$ & 36 Female & 7 Male \\
Focus group 1 & 6 Female & 6 Female \\
Focus group 2 & 6 Male & 2 Male \\
\hline
\end{tabular}

their independent roles as well as the importance of teamwork during the management of an obstetric emergency.

\section{Problem statement}

Various midwifery clinical skills are complex in nature and difficult to teach during an actual emergency. Postpartum haemorrhage $(\mathrm{PPH})$, which is the most common type of obstetric emergency, accounts for $25 \%$ of maternal deaths worldwide and the third most common cause of maternal mortality in South Africa (National Committee for Confidential Enquiries into Maternal Deaths 2014). Simulation of PPH as an emergency could be used to improve patient care outcomes by offering students an opportunity to improve their performance while reflecting on and learning from their mistakes until they get it right and before managing actual patients with the same emergency (Lestander, Lehto \& Engstrom 2016; Ness et al. 2010). The scenario on PPH requires prompt application of good clinical, decisionmaking and problem-solving skills. Students are required to think fast and use a combination of skills to manage their simulated patient successfully. According to Jeffries and Jeffries (2012), this type of complex learning promotes high expectations for both the learners and the educators.

Using the four phases of the experiential learning cycle, as described by Kolb (2014), this study aims to explore and describe the experiences of student midwives who used HFHPS in a $\mathrm{PPH}$ case scenario. The experiential learning cycle was used as a conceptual framework for data analysis, and therefore the findings of this study are linked to each phase of the cycle.

\section{Objective of the study}

The aim of the study was to explore how HFHPS can promote experiential learning of a midwifery clinical emergency such as $\mathrm{PPH}$.

\section{Definition of terms}

High-fidelity human patient simulators are computercontrolled mannequins that are designed to mimic an almost real-life interaction with students in a controlled simulated clinical setting (Jeffries \& Jeffries 2012).

Experiential learning is the construction of knowledge and meaning from real-life experiences related to a learner's future career (Yardley et al. 2012).

\section{Significance of the study}

The importance of this study is to explore experiential learning during classroom teaching by using HFHPS to enable students to manage an obstetric emergency such as $\mathrm{PPH}$ in the clinical setting.

\section{Research approach}

The researcher used a descriptive qualitative research approach to explore the views of student midwives who 
used HFHPS to learn to manage an obstetric emergency in a clinical skills laboratory.

\section{Research setting}

The research setting was a local university in KwaZulu-Natal, South Africa. The university offers a variety of nursing speciality programmes both at undergraduate and postgraduate (master's) level. The basic midwifery module is offered in the fourth year of the undergraduate programme. The nursing discipline has a fully functional clinical skills laboratory with high-, medium- and low-fidelity human patient simulators used in the teaching of nursing and medical students.

\section{Research participants}

The research participants were all fourth-year undergraduate student midwives (total population $=43$ ) who were enrolled in the midwifery module within an undergraduate baccalaureate of nursing programme. An all-inclusive sampling method was used in this study. Two groups of 6 student midwives (12 in total) participated in different roles in the $\mathrm{PPH}$ scenario (Table 1). The different roles in the team were deliberately included to maintain the realness of the situation and highlight the importance of teamwork when managing emergencies. The remaining 37 student midwives observed the scenario.

\section{Data collection process}

In 2015, the researcher and the research supervisor, after an extensive literature search, developed a draft simulation learning package on $\mathrm{PPH}$. The draft package was evaluated by a team of experts consisting of midwifery clinical specialists, midwifery educators, nursing education specialists and obstetricians within South Africa. The package was subsequently improved and used to teach undergraduate student midwives who were in the 2016 group. These student midwives were expected to read the guidelines and instructions in the package and volunteer to participate in a PPH scenario role-play. Two groups of six undergraduate student midwives took part in the $\mathrm{PPH}$ scenario role-play which used a HFHPS (SimMom). The simulation experience comprised a briefing session prior to commencing, the scenario on $\mathrm{PPH}$ and then a debriefing session. Although the majority of the participants were eager to participate, only six role-players per session were required for the scenario. The roles included that of a registered midwife (who was the team leader), two student midwives who were assistants to the team leader, a staff nurse to assist in recordkeeping, a husband who offered moral support to his wife (SimMom) and a doctor to show collaboration with medical staff during obstetric emergencies. These role-players were selected to authenticate a real-life setup of a PPH scenario in a labour or delivery suite. The researcher, together with the remaining 37 student midwives observed the simulation session in real time, via a video conferencing system. Each scenario lasted approximately 13 minutes. The debriefing session in the classroom occurred immediately after the scenario exercise. The purpose of the debriefing was to explore the experiences of student midwives who either role-played or observed the scenario on PPH. This included reflecting on the actions and/ or decisions made by themselves or by their peers by identifying gaps related to the actual management of $\mathrm{PPH}$ (Amod \& Brysiewicz 2017).

Following the educational activity, the researcher conducted and audio-recorded two separate focus group discussions to explore the views of student midwives regarding the $\mathrm{PPH}$ simulation learning experience. The first focus group (FG1) was conducted on the same day as the simulation exercise and included all the 12 participants who were role-players in the scenario. The researcher asked open-ended questions, which were linked to experiential learning (Box 1). The second focus group (FG2) was conducted a week later in the clinical area, and included another eight student midwives.

\section{Data analysis}

The data for this article were extracted from two separate focus groups which comprised 20 student midwives who participated as observers and role-players of the $\mathrm{PPH}$ scenario. The recordings of the focus groups were transcribed. Transcriptions were analysed by the researcher and the research supervisor using content analysis as described by Graneheim, Lindgren and Lundman (2017).

\section{Trustworthiness}

According to Cope (2014), trustworthiness refers to the quality value of the results and conclusions reached in a qualitative study. In this study, the researcher knew the participants who were fourth-year student midwives enrolled in the baccalaureate programme. A good rapport developed between the participants and the researcher who was their teacher and clinical facilitator. Participants were relaxed and comfortable throughout the data collection process.

The simulated scenario setup on PPH occurred under an almost natural circumstance, so that student midwives would interact in an almost real-life clinical situation. This was to provide sufficient details and to give the reader a sense of the path taken by the researcher. The researcher posed her preplanned questions, during the debriefing and focus group sessions. Participants were encouraged to express their views on their experience freely. The researcher provides an in-depth description to give the reader a sense of 'being there', as well as attempts to demonstrate that the knowledge acquired may be relevant to a similar situation. All data were analysed with

BOX 1: Questions posed in focus group.

1. How would you describe your experience in the simulation scenario?

2. Do you feel that the simulation scenario was beneficial to you?

2.1. If yes, what are some of the benefits that you identified?

2.2. If no, how can we improve the simulation scenario?

3. How do you feel about being able to manage a patient with postpartum haemorrhage following exposure to this type of learning?

4. Did the simulation scenario improve any skills?

4.1. If yes, what skills were challenged in the scenario?

4.2. How did the participation in the simulation affect your self-confidence?

5. Would you like to be involved in other midwifery simulation learning? 
the guidance of the research supervisor with whom frequent sessions were held to interpret the results.

\section{Ethical considerations}

The University Research Committee granted permission to conduct this study (reference number HSS/0320/015M). Each participant was provided an information sheet, explaining the purpose and nature of the study, prior to obtaining written consent. The participants were informed of their right to withdraw voluntarily at any stage of the study and that non-participation would not affect their education or classes in any manner. The right to privacy and confidentiality was maintained throughout the study.

\section{Results \\ Demographic data}

Forty-three undergraduate student midwives participated in the educational activity. There were 7 male and 36 female participants ranging between 21 and 35 years of age. Table 1 shows the gender demographics of participants of the educational activity. Of the total population, there were 12 student midwives who participated as role-players in a scenario on PPH. These 12 students were included in the FG1. The remaining student midwives observed the scenario together with the researcher. A FG2 was conducted a week later and included eight student midwives who participated as either role-players or observers of the PPH scenario. A total of 20 student midwives were included in the focus groups.

The data from these focus groups were coded and categorised using content analysis. The four categories that emerged from findings are discussed.

\section{Phase 1: Managing real-life emergencies (the concrete experience)}

The scenario on PPH incorporated the use of a high-fidelity mannequin (SimMom) which allowed student midwives an opportunity to experience an almost real-life emergency in a confined environment. Each role-player received an action card, which explained their role and expectations in the simulation exercise.

Theme 1: Good simulation of real complex environment: The scenario on PPH is a complex case scenario, which requires a combination of skills such as clinical competence, decision-making and problem-solving skills as is needed in real-life situations. These competencies are essential to learn to manage obstetric emergencies successfully. The scenario offered a unique opportunity for situated learning by allowing student midwives to practise realistic scenarios while becoming fully immersed in the situation. One participant role-player said:

'It [the scenario] was exciting and turned out good...I liked how decisions were made whilst waiting for the doctor.' (FG1, P1, female)
Another participant role-player added:

'It [the scenario] was good. Students were relaxed. They explained each step and it was nice to watch. I did not see a PPH case in real life, but this simulation helped me form an imagination on how I will do it in real life.' (FG1, P6, female)

The distinct roles clearly outlined inter-professional teamwork and added to the realness of the situation. These team roles are similar to what student midwives experience in their placement hospitals where such emergencies are common. One participant observer commented:

'It was a good practical experience. SimMom responds likes a real patient. You can speak to the SimMom and...monitor the vital signs.' (FG2, P6, female)

A second observer added:

'It is different from doing a competency, like we have been doing in the past years...with simulation you are able to learn whatever theory and then apply the practical.' (FG2, P4, female)

Theme 2: Simulation of a real environment may be challenging: Although most student midwives spoke about how they enjoyed the high-fidelity simulation experience, one student midwife stated that the experience was challenging. The role-player said:

'I found the experience to be challenging as I played the role of the doctor so I applied my learning experience.' (FG1, P2, male)

\section{Phase 2: Promoting reflection (reflective observation)}

Feedback is an essential aspect of simulation as it allows students to reflect on their roles, decisions and skills from their own learning experiences.

Theme 3: Reflection, though challenging, is helpful in the learning process: In this study, participants were encouraged to discuss their experience during a debriefing.

One participant observer said:

'I felt that it was very helpful...getting the students to do the simulation itself is a good way for us to practise our skills and it helped me.' (FG2, P1, female)

The results showed that participants found the experience to be new and helpful. They were able to assess their own performances and that of their peers.

One participant role-player said:

'It [the simulation] was an eye opener. I was able to identify gaps. It was similar to a real-life situation and very beneficial to my knowledge.' (FG1, P6, female)

\section{Phase 3: Thinking about learning (abstract conceptualisation)}

The purpose of using a high-fidelity simulator in a realistic scenario helps student midwives to practise a combination of learning outcomes such as knowledge, skills, satisfaction, confidence and critical thinking. When students are able to 
achieve these outcomes, they feel encouraged to partake in any similar real-life opportunity.

Theme 4: Facilitating thinking of future application of skills: These responses show that student midwives were able to reflect on their performance and thus evaluate their learning.

One participant who was the team leader in the scenario said:

'I was able to delegate effectively making sure the team knew what to do in terms of remembering. It is an easier method to learn from experiencing what is expected in a clinical situation.' (FG1, P6, female)

Another participant role-player said:

'After going through the simulation, I found that I understand much more. It helped me to actually know what I was doing and to highlight other areas where I need to develop further.' (FG1, P5, male)

A third participant role-player said:

'I feel confident to do it in the ward. The guidance was clear on what to expect in the wards, it may not be the exact same thing, but you will know the steps to follow.' (FG1, P2, male)

\section{Phase 4: Try out what was learnt (active experimentation)}

Learning, practising and mastering certain nursing procedures, and using high-fidelity simulation can encourage student midwives to become confident and 'hands on' in the practical situation. High-fidelity simulation prepares student midwives to use multiple skills simultaneously to manage an obstetric emergency (PPH) in an almost real-life scenario.

Theme 5: Linking simulation to practise: The participants identified that by applying the principles learnt during a scenario experience into a real-life situation, active experimentation can take place.

One participant who was observing the role-play commented:

'You know when I think back from the experience [I had] soon after we started this course, there was a patient having an eclamptic fit. I went [away] and started helping other patients because I didn't know what to do. But now that has changed especially in PPH because you feel that you won't stand but get involved and help.' (FG2, P6, female)

Another participant observer added:

'We also had a case and it was really easy. I helped with catheterising the patient, putting up IV lines and vital signs monitoring. I found it very similar to the simulation. I was able to relate back to it [the simulation experience] and see what they [the role-players] were saying and doing.' (FG2, P3, female)

One participant role-player quickly added:

'The fact that we were shining (giggling) then you become proud. It actually boosted our confidence in an emergency itself. When we qualify, we won't shy away.' (FG2, P1, female)

\section{Discussions}

\section{Phase 1}

The observers felt that by watching their peers participate in the simulation experience, they would also know what to do should such an emergency occur in a real-life situation. According to O'Regan et al. (2016), students value observer roles as it affords them an overview of details, and therefore observers are able to provide meaningful feedback during debriefing sessions. High levels of realism, during the high-fidelity simulation experience, forces students to engage actively, and according to Ness et al. (2010) and Neill and Wotton (2011) where the simulation scenario is authentic, students will act as if the situation is real.

Likewise, the concrete experience, as described by Kolb (2014), involves doing a task or having an experience. In this first phase of the experiential learning cycle, student midwives were able to 'feel' the experience by becoming actively involved in the situation. Previous studies, which used nursing students in complex high-fidelity simulations scenarios, also showed improvements on all learning outcomes, including critical thinking, confidence, competence and theory-practice integration (DeBourgh \& Prion 2011; Jeffries \& Jeffries 2012; Kaddoura et al. 2016).

It appears that by playing the role of a doctor in a team, there is an increased expectation from team members and this demands that you should know what to do in an emergency. Fry, Ketteridge and Marshall (2015) and Hill (2017) also saw similar results where students found the simulation experience to be fun and interactive as well as stressful and challenging. Role-playing in an obstetric emergency can be very challenging for students because of the complexity and urgency of the situation; however, when students are faced with an emergency, they may 'give of their best' and showcase a combination of skills to save the life of a patient. Allowing students an opportunity to play different roles in a simulation exercise can encourage them to understand how different people feel and respond in a real-life situation such as in the role of a doctor, a team leader, a student midwife or a birth companion. It also teaches students the importance of working quickly and harmoniously during an obstetric emergency to save the life of the patient.

\section{Phase 2}

According to Neill and Wotton (2011), simulation debriefing is central to the simulation event as it guides students through a reflection of what just occurred. Similarly, in the phase of reflective observation, in the experiential learning cycle, the learner takes time out from the task or experience to review what was experienced (Wain 2017). In this study, the results of the focus groups showed that the scenario caught the full attention of the observers who were fully engaged throughout these discussions. Student midwives who observed the simulation scenario were able to evaluate the simulation exercise, the performance of the role-players and their own gaps and strengths. Reflection and feedback 
promote the integration of theory and practice through the development of critical thinking, and when students reflect on their experience, it enriches experiential learning (Butler, Veltre \& Brady 2009; Lestander et al. 2016; McCormick 2014).

\section{Phase 3}

The participants were able to identify areas that needed improvement and felt that they would know what to do if they experience a similar situation in reality. These feelings of self-confidence and self-worth develop when students come to the realisation that they can apply their knowledge and make clinical judgements (Mikasa, Cicero \& Adamson 2013; Rourke, Schmidt \& Garga 2010). According to Kolb (2014), the abstract conceptualisation phase occurs when students make their own theories or conclusions about an experience. They attempt to make sense of what occurred and interpret the events of the experience to promote understanding (Fry et al. 2015; Hill 2017). Similarly, the debriefing of this simulation scenarios encouraged student midwives to critically reflect on their experience of learning and make their own assumptions about their knowledge, skills and abilities. Comments related to both the positive and negative aspects, and showed that student midwives were aware of important principles in nursing care. Lapkins and Levett-Jones (2011) attest that simulation provides students with a chance to develop clinical judgement and affords the faculty an opportunity to observe the students' clinical decision-making and practice in a confined, prescribed setting. Students who participate in simulation are forced to function at a higher cognitive level when they are faced with fast thinking and acting scenarios (Goodstone et al. 2013). According to Wain (2017), reflective practice increases self-awareness, selfidentity and personal growth that lead to job satisfaction and professional fulfilment.

\section{Phase 4}

It seems as if that prior to this session, participants felt less competent to be involved in procedures encountered in the clinical area. According to Kolb, the active experimentation phase involves the application of new theories and principles during decision-making and problem-solving activities. Wain (2017) describes that in this phase the learner applies what was learned into practice. Post-partum haemorrhage is a common obstetric emergency that requires a combination of these activities to manage a patient successfully and practising these skills helps student midwives to feel less anxious and more confident when faced with similar real-life situations. In this study, student midwives were fortunate to experience a similar scenario in real life and they felt confident to assist in the management of the patient. These results were mostly evident in the second focus group discussion, which revealed that student midwives are able to test or try out a combination of skills (practical, decision-making, problemsolving, critical thinking and clinical judgement) confidently in a real situation transferring the same principles of care used during the simulation experience.
High-fidelity human patient simulators used in complex scenarios offer student midwives the opportunity to manage real-life emergencies, reflect on their experience, evaluate how the experience has contributed to their learning outcomes and then incorporate the same principles or theories in a new situation. Through experiential learning and the use of high-fidelity simulation experiences, a link between classroom learning and the real working world becomes possible (Kolb 2014). High-fidelity human patient simulators used in a skills laboratory offer students an arena to practise their skills in certain procedures before actually conducting these procedures on real-life patients. This can be a good way to assist nurse educators to teach clinical skills which are difficult to teach in busy clinical placements or where clinical placement is limited (Berragan 2011).

Bergsteiner and Avery (2014), in their study, critically evaluated Kolb's experiential learning cycle and highlighted the divergent and overlapping classifications of learning activities with other philosophers such as Svinicki and Dixon (1987), Butler (1986) and Fleming (2001). This resulted in the reconceptualisation of Kolb's theory to a twin-cycle experiential learning model (TCELM) which accommodates both a concrete, active, primary learner and an abstract, passive, secondary learner. However, this new model was not used in a high-fidelity simulation experience previously.

\section{Summary}

High-fidelity human patient simulators allow nurse educators an opportunity to integrate Kolb's four-phase experiential learning to teach obstetric emergencies. The findings of this study are aligned to Kolb's experiential learning cycle and described as follows:

- The concrete experience - HFHPS offers student midwives an opportunity to experience and manage reallife emergencies.

- Reflective observations - HFHPS promotes an opportunity to reflect on the experience.

- Abstract conceptualisation - HFHPS allows student midwives to think about the learning experience.

- Active experimentation - HFHPS allows student midwives to act/try out what was learned.

\section{Recommendations}

High-fidelity simulation as a learning strategy has many possibilities for clinical nursing, and the impact of highfidelity simulation on clinical competence should be explored in future studies.

Evaluating the outcomes of HFHPS used for teaching purposes and its effects on actual patient care in terms of quality is also essential.

\section{Limitations}

The participants were known to the researcher, who was their teacher and clinical facilitator, and this may have 
influenced their responses. The study was limited to one setting.

\section{Conclusion}

High-fidelity human patient simulators allow nurse educators a platform to promote experiential learning in a safe environment and decrease the challenges faced in clinical accompaniment. Although some criticism exists against Kolb's experiential learning theory, it was well suited in this study to show how high-fidelity simulation in a PPH scenario promotes the four-phase cycle of experiential learning to role-players and student observers.

\section{Acknowledgements Competing interests}

The authors declare that they have no financial or personal relationships that may have inappropriately influenced them in writing this article.

\section{Authors' contributions}

The study was conceptualised, carried out and data were analysed by both authors. H.B.A. collected the data and P.B. was the research supervisor. Both authors drafted the manuscript.

\section{Reference}

Bergsteiner, H. \& Avery, G.C., 2014, 'The twin-cycle experiential learning model: Reconceptualising Kolb's theory', Studies in Continuing Education 36(3), 257-274. https://doi.org/10.1080/0158037X.2014.904782

Boet, S., Bould, M.D., Layat Burn, C. \& Reeves, S., 2014, 'Twelve tips for a successful interprofessional team-based high-fidelity simulation education session', Medical interprofessional team-based high-fidelity simulation education session', Med

Berragan, L., 2011, 'Simulation: An effective pedagogical approach for nursing?', Nurse Education Today 31(7), 660-663. https://doi.org/10.1080/0158037X.2014.904782

Bruppacher, H.R., Alam, S.K., LeBlanc, V.R., Latter, D., Naik, V.N., Savoldelli, G.L. et al., 2010, 'Simulation-based training improves physicians' performance in patien care in high-stakes clinical setting of cardiac surgery', The Journal of the American Society of Anesthesiologists 112(4), 985-992.

Butler, K.A., 1986, Learning and teaching style in theory and practice, revised 2nd edn., Learner's Dimension, Columbia, CT, pp. 314-317.

Butler, K.W., Veltre, D.E. \& Brady, D., 2009, 'Implementation of active learning pedagogy comparing low-fidelity simulation versus high-fidelity simulation in
paediatric nursing education', Clinical Simulation in Nursing 5(4), e129-e136. paediatric nursing education', Clinical Simulat
https://doi.org/10.1016/j.ecns.2009.03.118

Chan, C.K.Y., 2012, 'Exploring an experiential learning project through Kolb’s learning theory using a qualitative research method'. European Journal of Engineering theory using a qualitative research method, European Journal of Engine
Education 37(4), 405-415. https://doi.org/10.1080/03043797.2012.706596

Cope, D.G., 2014, 'Methods and meanings: Credibility and trustworthiness of qualitative research', Oncology Nursing Forum 41(1), 89-91. https://doi.org/ 10.1188/14.ONF

DeBourgh, G.A. \& Prion, S.K., 2011, 'Using simulation to teach prelicensure nursing students to minimize patient risk and harm', Clinical Simulation in Nursing 7(2), e47-e56. https://doi.org/10.1016/j.ecns.2009.12.009

Farooq, M., 2013, 'Classroom testing of the goal-oriented framework', NUAS. The Journal of Liberal Arts 9, 33-53.

Fleming, N.D., 2001, Teaching and learning styles: VARK strategies, 1st edn., New Zealand, Christchurch (ed.), IGI Global.

Flood, J.L., Thompson, J.N., Lovell, E., Field, S. \& Daub, K., 2011, 'High-fidelity patient simulations: A classroom learning tool', American Nurse Today 6(5), 36-38.

Fry, H., Ketteridge, S. \& Marshall, S., 2015, 'Understanding student learning', in H. Fry, S. Ketteridge \& S. Marshall (eds.), A handbook for teaching and learning in higher education: Enhancing academic practice, vol. 2, pp. 9-25, Routledge, London.

Goodstone, L., Goodstone, M.S., Cino, K., Glaser, C.A., Kupferman, K. \& Dember-Neal, T., 2013, 'Effect of simulation on the development of critical thinking in associate degree nursing students', Nursing Education Perspectives 34(3), 159-162.

Graneheim, U.H., Lindgren, B.M. \& Lundman, B., 2017, 'Methodological challenges in qualitative content analysis: A discussion paper', Nurse Education Today 56 29-34. https://doi.org/10.1016/j.nedt.2017.06.002
Hill, B., 2017, 'Research into experiential learning in nurse education', British Journal of Nursing 26(16), 932-938. https://doi.org/10.12968/bjon.2017.26.16.932

Jeffries, P.R. \& Jeffries, P.R., 2012, Simulation in nursing education: From conceptualization to evaluation, National League for Nursing, New York, p. 288.

Kaddoura, M., Vandyke, O., Smallwood, C. \& Gonzalez, K.M., 2016, 'Perceived benefits and challenges of repeated exposure to high fidelity simulation experiences of first degree accelerated bachelor nursing students', Nurse Education Today 36, 298-303. https://doi.org/10.1016/j.nedt.2015.07.014

Kolb, D.A., 2014, Experiential learning: Experience as the source of learning and development, Pearson Education Inc., FT Press, United States.

Lapkin, S. \& Levett-Jones, T., 2011, 'A cost-utility analysis of medium vs. High-fidelity human patient simulation manikins in nursing education', Journal of Clinical Nursing 20(23-24), 3543-3552. https://doi.org/10.1111/j.1365-2702.2011.03843.x

Lestander, O., Lehto, N. \& Engstrom, A., 2016, 'Nursing students' perceptions of learning after high fidelity simulation: Effects of a three-step post-simulation reflection model', Nurse Education Today 40, 219-224. https://doi.org/10.1016/j. nedt.2016.03.011

Lewis, R., Strachan, A. \& Smith, M.M., 2012, 'Is high fidelity simulation the most effective method for the development of non-technical skills in nursing? A review of the current evidence', The Open Nursing Journal 6, 82. https://doi.org/ 10.2174/1874434601206010082

Linder, L.A. \& Pulsipher, N., 2008, 'Implementation of simulated learning experiences for baccalaureate pediatric nursing students', Clinical Simulation in Nursing 4(3), e41-e47. https://doi.org/10.1016/j.ecns.2008.09.002

McCormick, K., 2014, 'The effects of learning styles, critical thinking disposition, and critical thinking on clinical judgement in senior baccalaureate nursing students during human patient simulation', PhD dissertation, Southern University, during human patient simulation', PhD
Agricultural and Mechanical College, pp. 123.

Mikasa, A.W., Cicero, T.F. \& Adamson, K.A., 2013, 'Outcome-based evaluation tool to evaluate student performance in high-fidelity simulation', Clinical Simulation in Nursing 9(9), e361-e367. https://doi.org/10.1016/j.ecns.2012.06.001

National Committee for Confidential Enquiries into Maternal Deaths, 2014, 'Saving Mothers 2011-2013: Sixth report on the Confidential Enquiries into Maternal deaths in South Africa', viewed 20 September 2018, from http://www.kznhealth gov.za/mcwh/Maternal/Saving-Mothers-2011-2013-Executive-Summary.pdf

Neill, M.A. \& Wotton, K., 2011, 'High-fidelity simulation debriefing in nursing education: A literature review', Clinical Simulation in Nursing 7(5), e161-e168. https://doi.org/10.1016/j.ecns.2011.02.001

Ness, V., Duffy, K., McCallum, J. \& Price, L., 2010, 'Supporting and mentoring nursing students in practice', Nursing Standard 25(1), 141-146. https://doi.org/10.7748/ ns.25.1.41.s55

O’Regan, S., Molloy, E., Watterson, L. \& Nestel, D., 2016, 'Observer roles that optimise learning in healthcare simulation education: A systematic review', Advances in Simulation 1, 4. https://doi.org/10.1186/s41077-015-0004-8

Phipps, M.G., Lindquist, D.G., McConaughey, E., O’brien, J.A., Raker, C.A. \& Paglia, M.J., 2012, 'Outcomes from a labor and delivery team training program with simulation component', American Journal of Obstetrics and Gynecology 206(1) 3-9. https://doi.org/10.1016/j.ajog.2011.06.046

Powell-Laney, S., Keen, C. \& Hall, K., 2012, 'The use of human patient simulators to enhance clinical decision-making of nursing students', Education for Health 25(1), 11. https://doi.org/10.4103/1357-6283.99201

Riley, W., Davis, S., Miller, K., Hansen, H., Sainfort, F. \& Sweet, R., 2011, ‘Didactic and simulation nontechnical skills team training to improve perinatal patient outcomes in a community hospital', The Joint Commission Journal on Quality and Patient Safety 37(8), 357-364. https://doi.org/10.1016/S1553-7250(11)37046-8

Rourke, L., Schmidt, M. \& Garga, N., 2010, 'Theory-based research of high fidelity simulation use in nursing education: A review of the literature', International Journal of Nursing Education Scholarship 7(1), 1-14. https://doi.org/10.2202/1548923X.1965

Stocker, M., Burmester, M. \& Allen, M., 2014, 'Optimisation of simulated team training through the application of learning theories: A debate for a conceptual framework', BMC Medical Education 14(1),69. https://doi.org/10.1186/1472framework,

Sundler, A.J., Pettersson, A. \& Berglund, M., 2015, 'Undergraduate nursing students' experiences when examining nursing skills in clinical simulation laboratories with high-fidelity patient simulators: A phenomenological research study', Nurse Education Today 35(12), 1257-1261. https://doi.org/10.1016/j.nedt.2015.04.008

Svinicki, M.D. \& Dixon, N.M., 1987, 'The Kolb Model modified for classroom activities', College Teaching 35(4), 141-146. https://doi.org/10.1080/87567555.1987.9925469

Wain, A., 2017, 'Learning through reflection', British Journal of Midwifery 25(10), 662-666. https://doi.org/10.12968/bjom.2017.25.10.662

Wolfgram, L.J. \& Quinn, A.O.L., 2012, 'Integrating simulation innovatively: Evidence in teaching in nursing education', Clinical Simulation in Nursing 8(5), e169-e175. https://doi.org/10.1016/j.ecns.2010.09.002

Amod, B.H. \& Brysiewicz, P., 2017, 'Developing, implementing and evaluating a simulation-learning package on post-partum haemorrhage for undergraduate midwifery students in KwaZulu-Natal', Health SA Gesondheid 22, 194-201. https://doi.org/10.1016/j.hsag.2016.11.004

Yardley, S., Teunissen, P.W. \& Dornan, T., 2012, 'Experiential learning: Transforming theory into practice', Medical Teacher 34(2), 161-164. https://doi.org/10.3109/0 142159X.2012.643264

Zigmont, J.J., Kappus, L.J. \& Sudikoff, S.N., 2011, 'The 3D model of debriefing: Defusing, discovering, and deepening', Seminars in Perinatology 35(2), 52-58. https://doi.org/10.1053/j.semperi.2011.01.003 